\title{
EVALUASI KINERJA JARINGAN IRIGASI AIR TANAH GUNA PENINGKATAN PEMENUHAN KEBUTUHAN AIR IRIGASI PADA DAERAH IRIGASI DI KABUPATEN TIMOR TENGAH UTARA (STUDI KASUS DI KECAMATAN INSANA UTARA)
}

\author{
Indradhi Lasmana ${ }^{1}$, Yohana Millo ${ }^{2}$ \\ ${ }^{1}$ Dosen Jurusan Teknik Sipil Politeknik Negeri Kupang \\ E-mail : indradhi.lasmana@pnk.ac.id \\ ${ }^{2}$ PLP Jurusan Teknik Sipil Politeknik Negeri Kupang
}

\begin{abstract}
Abstrak
Dalam mencapai ketahanan dan kemandirian pangan melalui peningkatan produksi pangan khususnya beras di Propinsi Nusa Tenggara Timur, pemanfaatan air tanah dapat digunakan sebagai air irigasi di daerah-daerah yang kekurangan air. Seiring dengan waktu pemanfaatannya dan usia guna pada beberapa sumur bor untuk Jaringan irigasi air tanah (JIAT) di Kecamatan Insana Utara kabupaten Timor Tengah Utara, mesin pompa maupun jaringannya mengalami penurunan. Bahkan dibeberapa titik lokasi (banyak sistem jaringan Air Tanah tersebut tidak berfungsi. Perlu dilakukannya evaluasi kinerja jaringan irigasi air tanah guna meningkatkan pemenuhan kebutuhan airi irigasi di Kabupaten Timor Tengah Utara umumnya dan kecamatan Insana Utara khususnya. Penelitian evaluasi kinerja jaringan irigasi air tanah di kabupaten Timor Tengah Utara di lakukan di kecamatan Insana Utara. Terdapat 5 Sumur bor di Kecamatan Insana Utara Kabupaten Timor Tengah Utara yang pemanfaatan untuk Jaringan irigasi air tanah (JIAT) yaitu Sumur POI-90, POI-91, POI-92,POI-93 dan sumur POI-95 dengan total daerah layanan sawah seluas $+49 \mathrm{Ha}$. Dari hasil identifikasi masing-masing sumur tersebut menunjukan 2 sumur (POI-90, POI-92) Rumah pompa dalam kondisi rusak berat, 5 Sumur menunjukkan mesin dan pompa mengalami kerusakan, 3 Sumur (POI-90, POI-91, POI-92) system jaringan pipa mengalami kerusakan termasuk asesoriesnya. Hasil evaluasi penilaian Kinerja jaringan irigasi air tanah (JIAT) yang meliputi komponen (1) prasarana fisik, (2) Produktifitas tanaman, (3) Sarana penunjang, (4) Organisasi personalia, (5) Dokumentasi JIAT (6) Petani Pemakai Air Tanah (P3AT) masing diperoleh : Sumur POI-90 = $35 \%$, POI-91 $=30 \%$, Sumur POI- $92=10 \%$, Sumur POI-93 $=31 \%$ dan Sumur POI-95 $=32 \%$. Kriteria yang diperoleh dari 5 sumur bor tersebut menunjukkan kinerja jaringan irigasi air tanah (JIAT) adalah kinerja Buruk/jelek dan perlu perhatian $(<50 \%)$. Untuk memenuhi kebutuhan air irigasi pada lahan di masing lokasi perlu dilakukan perbaikan.
\end{abstract}

Kata kunci: Kinerja, Jaringan irigasi air tanah (JIAT).

\section{PENDAHULUAN}

Untuk wilayah Nusa Tenggara Timur (NTT) ketersediaan air untuk pertanian merupakan masalah yang cukup pelik karena faktor curah hujan yang minim serta kondisi geologi yang porous dan topografi yang cenderung curam. Pada beberapa wilayah terdapat cukup sumber air permukaan untuk pertanian dengan pembangunan bendung, bendungan, embung maupun captering. Namun pada banyak wilayah justru memerlukan intervensi dengan teknologi yang lebih untuk menampung dan memperoleh ketersediaan air seperti pemanfaatan geotextile/geomembrane ataupun explorasi/eksploitasi sumur dalam untuk pertanian dengan menggunakan mesin pompa air yang disebut Jaringan Irigasi Air Tanah (JIAT).
Pemanfaatan air tanah dalam haruslah sesuai daya dukung akuifer setempat yang penggunaannya diatur dengan perangkat kebijakan yaitu Undang-undang Sumber Daya Air No. 7 Tahun 2004, Peraturan Pemerintah No. 43 Tahun 2008 tentang Air Tanah serta Peraturan Daerah. Seiring dengan waktu pemanfaatannya dan usia guna pada beberapa sumur bor untuk Jaringan irigasi air tanah (JIAT) di Kecamatan Insana Utara kabupaten Timor Tengah Utara, mesin pompa maupun jaringannya mengalami penurunan. Bahkan dibeberapa titik lokasi (banyak sistem jaringan Air Tanah tersebut tidak berfungsi. Beberapa permasalahan yang terjadi pada infrastruktur JIAT antara lain kondisi Rumah pompa, Mesin penggerak \& pompa, Jaringan pipa, Box, Air valve yang sudah tidak layak atau rusak. Kondisi tersebut menyebabkan tidak optimalnya pelayanan 
terhadap lahan sawah yang ada, dan akibatnya banyak lahan sawah yang tidak berfungsi, terbengkalai tanpa pemanfaatan lagi

Permasalahan usia guna dari mesin pompa maupun jaringannya yang mengalami penurunan bahkan sistem jaringan Air Tanah tersebut tidak berfungsi. Kondisi tersebut menyebabkan tidak optimalnya pelayanan terhadap lahan sawah yang ada, dan akibatnya banyak lahan sawah yang tidak berfungsi, terbengkalai tanpa pemanfaatan lagi. Permasalahan dalam penelitian ini dapat dirumuskan sebagai berikut : Melakukan Identifikasi kondisi Infrastruktur Jaringan Irigasi Air Tanah (JIAT) yang ada di Kabupaten Timor Tengah Utara, Bagaimana kinerja sistem Jaringan Irigasi Air Tanah (JIAT) yang ada saat ini, Bagaimana upaya-upaya penanganan terhadap sistem Jaringan Irigasi Air Tanah (JIAT) berdasarkan hasil evaluasi kinerja tersebut.

Tujuan penelitian ini adalah mengetahui kondisi dan penyebab penurunan keberfungsian Infrastruktur serta mengevaluasi kinerja sistem Jaringan Irigasi Air Tanah (JIAT) sehingga dapat dilakukan upaya-upaya penanganan kerusakan yang terjadi. Manfaat dari penelitian ini adalah Memberikan informasi serta membantu menyelesaikan masalah pada kinerja sistem jaringan irigasi air tanah, sehingga dapat dilakukan upaya perbaikan dan pemanfaatan oleh pemerintah yang pada akhir dapat memenuhi kebutuhan air irigasi dalam rangka peningkatan swasembada pangan

\section{TINJAUAN PUSTAKA}

Berdasarkan keputusan menteri no. 32 tahun 2007, irigasi adalah usaha penyediaan, pengaturan, dan pembuangan air irigasi untuk menunjang pertanian yang meliputi permukaan, rawa, air bawah tanah, pompa dan tambak. Menurut Direktorat Jenderal Pengelolaan Lahan dan Air tahun 2009, irigasi adalah usaha penyediaan, pengaturan, dan pembuatan bangunan air untuk menunjang usaha pertanian, termasuk di dalamnya tanaman pangan, hortikultura, perkebunan, dan peternakan.

Irigasi tidak hanya digunakan untuk mendistribusikan air, ada juga beberapa fungsi irigasi antara lain:

1. Membasahi tanah, hal ini merupakan salah satu tujuan terpenting karena tumbuhan banyak memerlukan air selama masa tumbuhnya. Pembasahan tanah ini bertujuan untuk memenuhi kekurangan air apabila hanya ada sedikit air hujan.

2. Merabuk tanah atau membasahi tanah dengan air sungai yang banyak mengandung mineral.

3. Mengatur suhu tanah agar tanaman dapat tumbuh dengan baik dengan suhu yang optimal. Air irigasi dapat membantu tanaman untuk mencapai suhu yang optimal tersebut.

4. Membersihkan tanah dengan tujuan untuk menghilangkan hama tanaman seperti ular, tikus, serangga, dan lain-lain. Selain itu dapat juga membuang zat-zat yang tidak dibutuhkan oleh tanaman ke saluran pembuang.

5. Memperbesar ketersediaan air tanah karena muka air tanah akan naik apabila digenangi air irigasi yang meresap. Dengan naiknya muka air tanah, maka debit sungai pada musim kemarau akan naik

\section{Klasifikasi Jaringan Irigasi}

Untuk klasifikasi jaringan irigasi apabila ditinjau dari segi pengaturannya maka dapat dibedakan menjadi tiga jenis yakni:

\section{a. Jaringan irigasi sederhana}

Di dalam irigasi sederhana, pembagian air tidak diukur dan diatur sehingga kelebihan air yang ada pada suatu petak akan dialirkan ke saluran pembuang. Pada jaringan ini terdapat beberapa kelemahan antara lain adanya pemborosan air, sering terjadi pengendapan, dan pembuangan biaya akibat jaringan serta penyaluran yang harus dibuat oleh masingmasing desa.

b. Jaringan irigasi semi teknis

Di dalam irigasi jaringan semi teknis, bangunan bendungnya terletak di sungai lengkap dengan pintu pengambilan tanpa bangunan pengukur di bagian hilirnya. Beberapa bangunan permanen biasanya sudah dibangun di jaringan saluran. Bangunan pengaliran dipakai untuk melayani daerah yang lebih luas dibanding jaringan irigasi sederhana.

\section{c. Jaringan irigasi teknis}

Pada jaringan irigasi teknis, saluran pembawa, dan saluran pembuang sudah benar-benar terpisah. Pembagian air dengan menggunakan jaringan irigasi teknis adalah merupakan yang paling effektif karena mempertimbangkan waktu seiring merosotnya kebutuhan air. Pada 
irigasi jenis ini dapat memungkinkan dilakukan pengukuran pada bagian hilir. Pekerjaan irigasi teknis pada umumnya terdiri dari:

a. Pembuatan bangunan penyadap yang berupa bendung atau penyadap bebas.

b. Pembuatan saluran primer (induk) termasuk bangunan-bangunan didalamnya seperti bangunan bagi, bangunan bagi sadap, dan bangunan sadap. Bangunan ini dikelompokkan sebagai bangunan air pengatur, disamping itu ada kelompok bangunan air pelengkap diantaranya bangunan terjun, got miring, gorong-gorong, pelimpah, talang, jembatan, dan lain-lain.

c. Pembuatan saluran sekunder, termasuk bangunan-bangunan didalamnya seperti bangunan bagi-sadap, dan bangunan pelengkap seperti yang ada pada saluran induk.

d. Pembuatan saluran tersier termasuk bangunan-bangunan didalamnya, seperti boks tersier, boks kuarter, dan lain-lain.

e. Pembuatan saluran pembuang sekunder dan tersier termasuk bangunan goronggorong pembuang.

\section{Pengertian Air Tanah}

Air tanah adalah salah satu bentuk air yang berada di sekitar bumi kita dan terdapat di dalam tanah. Air tanah pada umumnya terdapat dalam lapisan tanah baik dari yang dekat dengan permukaan tanah sampai dengan yang jauh dari permukaan tanah. Ait tanah ini merupakan salah satu sumber air, ada saatnya air tanah ini bersih tetapi terkadang keruh sampai kotor, tetapi pada umumnya terlihat jernih. Air tanah yang jernih ini umumnya terdapat di daerah pegungungan dan jauh dari daerah industri, sehingga biasanya penduduk dapat langsung mengkonsumsi air ini, sedangkan air tanah yang terdapat di daerah industri sering kali tercemar, jika pihak industri kurang peduli akan lingkungan, dan air tanah yang terdapat di daerah perkotaan pada umumnya masih baik, tetapi tidak dapat langsung dikonsumsi. Air tanah yang tercemar umumnya diakibatkan oleh ulah masusia yang kurang bahkan tidak perduli akan lingkungan sekitar.

\section{Macam Air yang terdapat di Bumi}

1. Air Permukaan adalah air yang berada di atas permukaan tanah dan air ini biasanya terlihat langsung, seperti, air sungai sampai air laut, air danau. Air Tanah jenis ini dapat kita bagi lagi berdasarkan daerahnya, antara lain :

a. Air yang berada di daerah daratan, air selokan, air sumur permukaan, air sungai, air danau dan air yang berada di rawa

b. Air yang berada di daerah laut, yang kita kenal dengan air laut.

2. Air Tanah adalah air yang berada dalam tanah. Air Tanah ini dapat kita bagi menjadi 2 jenis :

a. Air Tanah Freatis adalah air yang terletak tidak jauh dari permukaan tanah serta berada di atas lapisan kedap air / impermeable.

b. Air Tanah Artesis adalah air tanah yang letaknya jauh di dalam tanah, umumnya berada diantara dua lapisan yang kedap air. Menurut asalnya air tanah dapat dibedakan menjadi :

- Air tanah yang berasal dari atmosfer (angkasa) dan dikenal dengan nama Meteoric Water, yaitu air tanah berasal dari hujan dan pencairan salju.

- Air tanah yang berasal dari dalam perut bumi, seperti Air Tanah Turbir (yaitu air tanah yang tersimpan di dalam batuan sedimen).

- Air Tanah Juvenil yaitu air tanah yang naik dari magma bila gas yang ada dilepaskankan melalui mata air panas.

\section{Proses Terbentuknya Air Tanah}

Air laut karena panas matahari berubah menjadi uap air. Oleh angin uap air tersebut ditiup ke atas daratan, pada tempat yang berelevasi tinggi uap tersebut akan mengalami pemampatan, dan setelah titik jenuhnya terlampaui akan jatuh kembali ke bumi sebagai air hujan. Air hujan sebagian besar akan mengalir di permukaan sebagai air permukaan seperti sungai, danau, atau rawa. Sebagian kecil akan meresap ke dalam tanah, yang bila meresap terus hingga zona jenuh akan menjadi air tanah

Bagian yang meresap dekat permukaan akan diuapkan kembali lewat tanaman yang kita kenal dengan evapotranspiration. Penguapan evaporation terjadi langsung pada tubuh air yang terbuka. Sedangkan aliran permukaan akan bermuara kembali ke laut, dan proses hidrogeologi di atas akan berlangsung lagi, demikian seterusnya. Selain air sungai dan air hujan, air tanah juga mempunyai peranan yang sangat penting terutama dalam menjaga keseimbangan dan ketersediaan bahan baku air untuk kepentingan rumah tangga maupun untuk kepentingan industri. Dibeberapa daerah, ketergantungan pasokan air bersih dan air tanah telah mencapai $\pm 70 \%$. Sebenarnya di bawah permukaan tanah terdapat kumpulan air yang mempersatukan kumpulan air yang 
ada di permukaan.

Kumpulan air inilah yang disebut air tanah. Air bawah tanah atau sering disangka dengan air tanah, adalah air yang terdapat pada ruang antar butir batuan atau celah-celah batuan. Letak air tanah dapat mencapai beberapa puluh bahkan beberapa ratus meter di bawah permukaan bumi. Lapisan batuan ada yang lolos air atau biasa disebut permeable dan ada pula yang tidak lolos atau kedap air yang biasa disebut impermeable. Lapisan lolos air misalnya terdiri dari kerikil, pasir, batuapung, dan batuan yang retak-retak, sedangkan lapisan kedap air antara lain terdiri dari napal dan tanah liat atau tanah lempung. Sebetulnya tanah lempung dapat menyerap air, namun setelah jenuh air, tanah jenis ini tidak dapat lagi menyerap air. Air tanah terbentuk berasal dari air hujan dan air permukan, yang meresap (infiltrate) mulamula ke zona tak jenuh (zone of aeration) dan kemudian meresap makin dalam (percolate) hingga mencapai zona jenuh air dan menjadi air tanah. Air tanah adalah salah satu fase dalam daur hidrologi, yakni suatu peristiwa yang selalu berulang dari urutan tahap yang dilalui air dari atmosfer ke bumi dan kembali ke atmosfer; penguapan dari darat atau laut atau air pedalaman, pengembunan membentuk awan, pencurahan, pelonggokan dalam tanih atau badan air dan penguapan kembali (Kamus Hidrologi, 1987).

Dari daur hidrologi tersebut dapat dipahami bahwa air tanah berinteraksi dengan air permukaan serta komponen-komponen lain yang terlibat dalam daur hidrologi termasuk bentuk topografi, jenis batuan penutup, penggunaan lahan, tetumbuhan penutup, serta manusia yang berada di permiukaan. Air tanah dan air permukaan saling berkaitan dan berinteraksi. Setiap aksi pemompaan, pencemaran terhadap air tanah akan memberikan reaksi terhadap air permukaan, demikian sebaliknya

\section{Kebutuhan air irigasi}

Kebutuhan air irigasi adalah kebutuhan air total yang akan diberikan pada petak sawah yang merupakan kebutuhan air untuk pengolahan tanah dan pertumbuhan tanaman. Kebutuhan bersih air di sawah dihitung dengan rumus :

dimana :

NFR = Kebutuhan air bersih di sawah (mm/hari)

Etc = Evapotranspirasi aktual atau penggunaan konsumtif tanam selama pertumbuhan ( $\mathrm{mm} / \mathrm{hari})$

$$
\begin{aligned}
& \mathrm{P} \quad=\text { Perkolasi } \\
& \mathrm{Re}=\text { hujan efektif ( } \mathrm{mm} / \text { hari) } \\
& \text { WLR = Penggantian lapisan air } \\
& \text { (mm/hari) }
\end{aligned}
$$

Kebutuhan air disawah untuk tanaman padi ditentukan oleh beberapa faktor antara lain :

1) Untuk penyiapan lahan

2) Penggunaan air untuk konsumtif Evapotranspirasi

3) Koefisien Tanaman (kc)

4) Perkolasi

5) Penggantian Lapisan Air

6) Perhitungan Hujan Efektif

7) Efisiensi Irigasi

\section{Tingkat Pelayanan Irigasi}

Berdasarkan Peraturan Menteri

Pekerjaan Umum dan Perumahan Rakyat (Permen PUPR) Nomor 23/PRT/M/2015 Tentang Pengelolaan Aset Irigasi, Tingkat pelayanan irigasi merupakan elemen penting dalam PAI, karena Investasi yang dilakukan dalam PAI harus dikaitkan dengan tingkat pelayanan irigasi tersebut.

Dalam peraturan menteri ini telah ditentukan bahwa tingkat pelayanan yang akan diukur adalah kinerja sistem irigasi.

Untuk dapat menghitung kinerja sistem irigasi perlu dihitung kondisi prasarana (kinerja jaringan irigasi) yang dilakukan dengan beberapa asumsi sebagai berikut:

1) Jaringan Irigasi baru dianggap mempunyai fungsi $100 \%$ dengan masingmasing aset dalam jaringan tersebut berfungsi $100 \%$.

2) Fungsi suatu aset bangunan akan berpengaruh terhadap seluruh luasan yang dilayani oleh bangunan tersebut (fungsi bendung akan berpengaruhterhadap seluruh luas jaringan irigasi, sedangkan fungsi bangunan bagi paling ujung hanya berpengaruh terhadap luasan dipetak yang dilayaninya)

3) Dalam hal pada suatu saluran terdapat bangunan, maka kondisi dari fungsi layanan yang membatasi adalah yang kondisi fungsi layanannya terkecil (jika salurannya masih $100 \%$ tetapi kemudian ada syphon yang hanya berfungsi $50 \%$, maka fungsi layanan terhadap jaringan irigasi di hilir syphon tersebut menjadi $50 \%$ saja). Prinsip-prinsip tersebut di atas diterapkan terhadap seluruh jaringan.

Penentuan kinerja individual aset 
236 | Jurnal Teknik Sipil (JUTEKS), Vol. III No. 3 01/04/2018

jaringan diekpresikan sebagai fungsi dari masing-masing aset, yang dalam pedoman ini dikelompokkan menjadi 4 (empat), yaitu:

a) baik sekali (>90\%);

b) baik (antara $70 \%-90 \%$ );

c) sedang(antara $55 \%-69 \%$ ); dan

d) buruk $(<55 \%)$. 

EVALUASI KINERJA JARINGAN IRIGASI AIR TANAH GUNA PENINGKATAN PEMENUHAN KEBUTUHAN AIR IRIGASI PADA DAERAH IRIGASI DI KABUPATEN TIMOR TENGAH UTARA

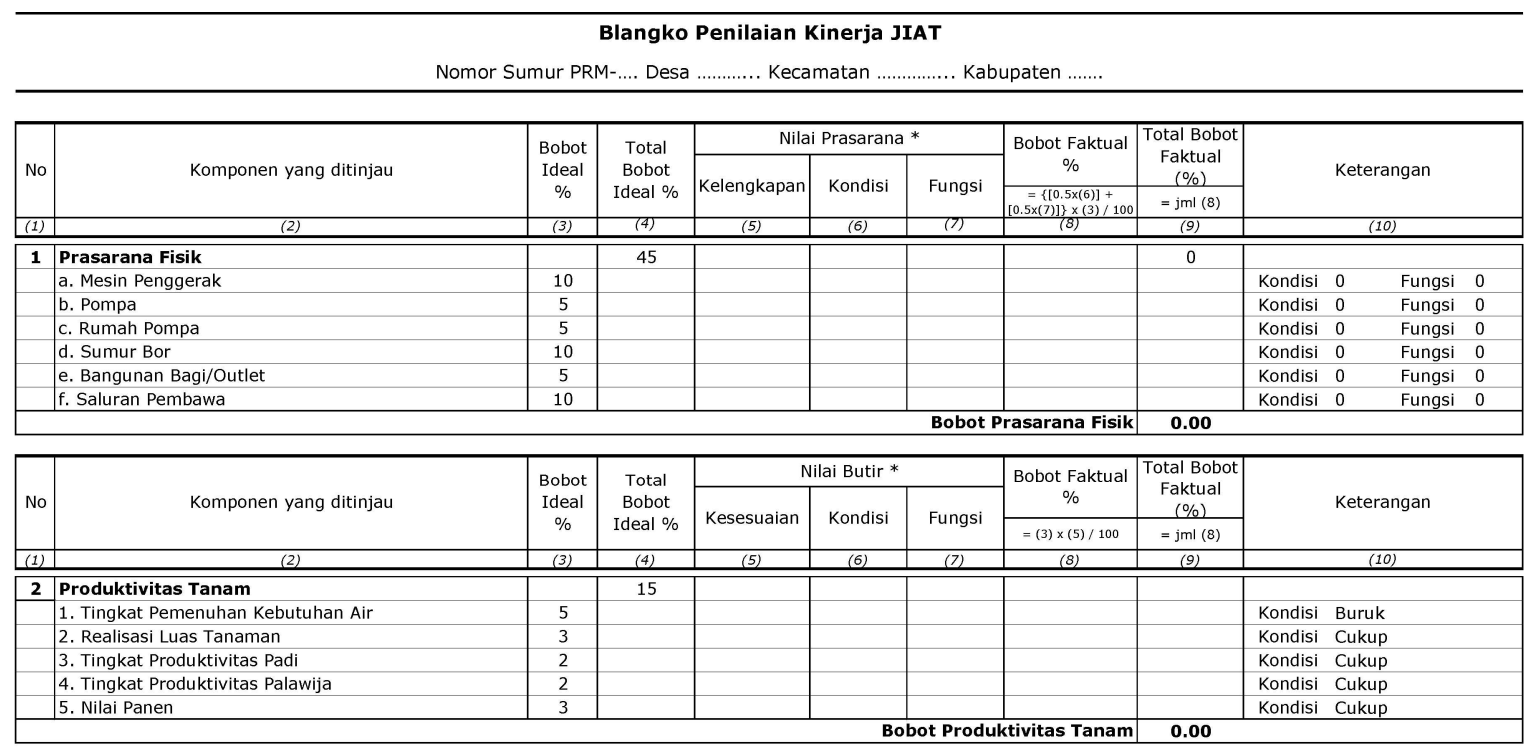

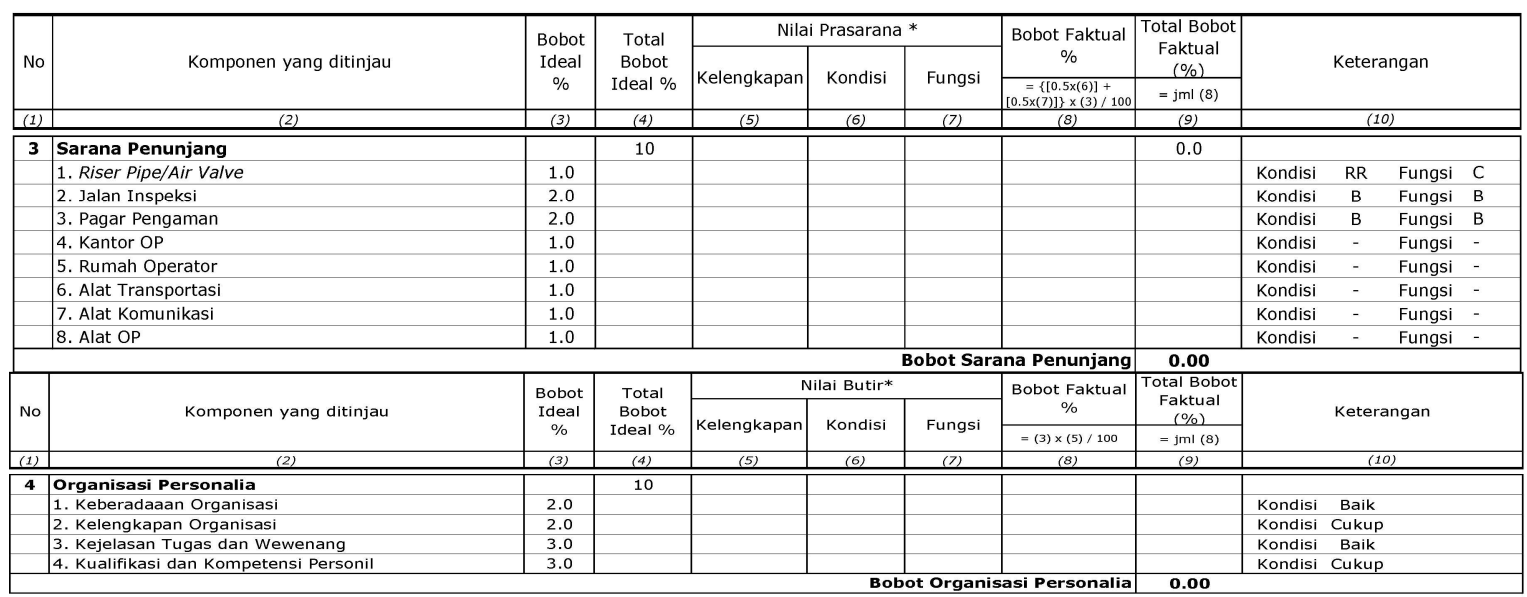

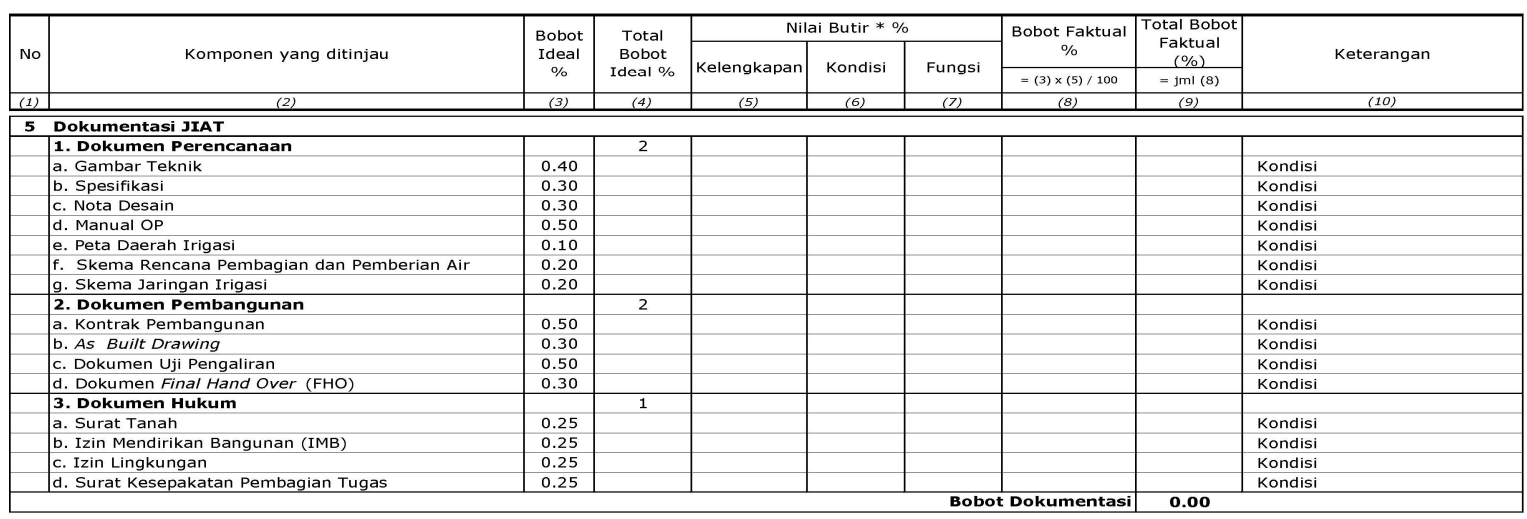

\begin{tabular}{|c|c|c|c|c|c|c|c|c|c|}
\hline \multirow[b]{2}{*}{ No } & \multirow[b]{2}{*}{ Komponen yang ditinjau } & \multirow{2}{*}{$\begin{array}{l}\text { Bobot } \\
\text { Ideal } \\
\%\end{array}$} & \multirow{2}{*}{$\begin{array}{c}\text { Total } \\
\text { Bobot } \\
\text { Ideal \% }\end{array}$} & \multicolumn{3}{|c|}{ Nilai Butir* } & \multirow{2}{*}{$\begin{array}{c}\text { Bobot Faktual } \\
\%\end{array}$} & \multirow{2}{*}{$\begin{array}{c}\text { Total Bohot } \\
\text { Faktual } \\
(\%) \\
\end{array}$} & \multirow[b]{2}{*}{ Keterangan } \\
\hline & & & & Kelengkapan & Kondisi & Fungsi & & & \\
\hline (1) & (2) & (3) & (4) & $(5)$ & $(6)$ & $(7)$ & (8) & (9) & $(10)$ \\
\hline 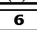 & Petani Pemakai Air Tanah (P3AT) & & 15 & & & & & 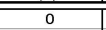 & \\
\hline & 2. Peran Aktif P3AT dalam pelaksanaan operasi JIAT & 2.0 & & & & & & & Kondisi \\
\hline & 3. Partisipasi P3AT dalam penanganan kerusakan JIAT & 2.0 & & & & & & & Kondisi \\
\hline & 4. Kesediaan P3AT untuk pembiayaan kegiatan OP & 1.0 & & & & & & & Kondisi \\
\hline & 5. Pelaksanaan Pertemuan Rutin & 1.0 & & & & & & & Kondisi \\
\hline & 6. Kelengkapan struktur organisasi & 1.0 & & & & & & & Kondisi \\
\hline
\end{tabular}




\section{METODE PENELITIAN}

Beberapa aspek yang terkait dengan metode penelitian yang akan digunakan untuk mencapai tujuan dari penelitian ini. Beberapa aspek tersebut meliputi : lokasi dan waktu penelitian, metode penelitian, sampling dan teknik pengambilan sampel, sumber data dan teknik pengambilan data, teknik pengolahan data dan teknik analisis data.

\section{Lokasi Penelitian}

Yang menjadi obyek penelitian ini yaitu Infrastrukstur Jaringan Irigasi Air Tanah (JIAT) di Kabupaten Timor Tengah Utara Kecamatan Insana Utara

\section{Metode Penelitian}

Pada studi ini metode yang dipakai adalah Deskriptif Evaluatif, yaitu metode studi yang mengevaluasi kondisi obyektif / apa adanya pada suatu keadaan yang sedang menjadi obyek studi ( Supriharyono, 2002 ). Analisis yang dipergunakan dalam penelitian ini adalah analisis diskriptif kualitatif yaitu penelitian yang bertujuan menggambarkan secara tepat sifat-sifat suatu individu, keadaan atau gejala tertentu pada lokasi penelitian.

\section{Sumber Data dan Teknik Pengumpulan Data}

Data yang dipakai sebagai bahan analisis dalam penelitian ini adalah data primer dan data sekunder.

\section{Tahapan Penelitian}

1. Pengumpulan data primer dan sekunder Adapun data primer yang diperlukan meliputi : Kondsisi existing jaringan irigasi air tanah (JIAT), Partisipasi masyarakat terhadap pengelolaan sistem jaringan irigasi air tanah (JIAT).

Adapun data primer yang diperlukan meliputi : Data spasial antara lain : Peta topografi., Peta Skema Jaringan, Data hidrologi

2. Identifikasi Permasalahan dan

Inventarisasi Kondisi Eksisting

Inventarisir semua komponen sistem Jaringan Irigasi Air Tanah, baik saluran maupun bangunan pendukungnya, jika data tidak tersedia, ukur dimensi saluran, pipa dan/atau segmen saluran, pipa serta bangunan lainnya, melakukan cek lapangan untuk memastikan kondisi yang ada sesuai dengan data, mencatat permasalahan utama yang terjadi pada masingmasing lokasi dan bangunan lainnya beserta foto kondisinya.

3. Analisis

Penilaian kinerja asset JIAT untuk menilai berapa besar tingkat layanan asset tersebut pada kondisi saat ini. Kegiatan ini berpedoman kepada PERMEN PUPR NO. 23 Tahun 2015 tentang "Teknis Perencanaan Pengelolaan Aset Irigasi”..

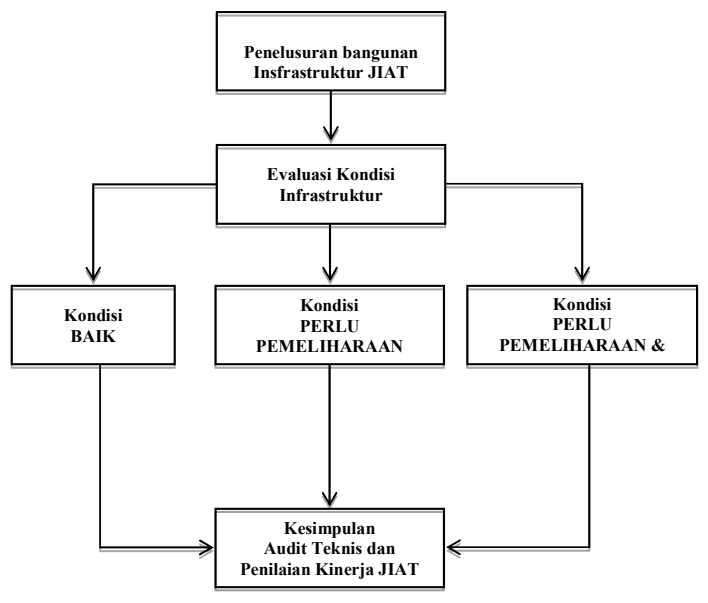

Gambar 1 Bagan alir penelitian

\section{HASIL DAN PEMBAHASAN}

\section{Kondisi Geografis}

Kabupaten TTU terletak pada koordinat antara 9 $02^{\prime} 48^{\prime \prime}$ LS - 9 9 $37^{\prime} 36^{\prime \prime}$ LS dan $124^{\circ} 04^{\prime} 02^{\prime \prime}$ BT - 12446'00" BT. Secara administrasi Kabupaten TTU memiliki batasbatas wilayah sebagai berikut : Sebelah Utara dengan Wilayah Ambenu (Timor Leste) dan Laut Sawu, Sebelah Selatan dengan Kabupaten Timor Tengah Selatan, Sebelah Barat dengan Kabupaten Timor Tengah Selatan dan Kabupaten Kupang, Sebelah Timur dengan Kabupaten Belu dan Malaka.

Wilayah Kabupaten TTU memiliki Kabupaten Timor Tengah Utara adalah $2.669,70 \mathrm{~km}^{2}$ dan berdasarkan Peraturan Daerah No. 08 Tahun 2007, Kabupaten TTU terdiri dari 24 Kecamatan, 160 Desa, 33 kelurahan, 525 Dusun, 757 RW (Rukun Warga), dan 2.114 RT (Rukun Tetangga).

Kecamatan Insana Utara terdiri dari 5 Desa dengan luas wilayah mencapai 53,84 $\mathrm{Km} 2 .=$ dengan jumlah penduduk mencapai 9.778 jiwa dengan rincian 4.898 jiwa laki-laki dan 4.880 jiwa perempuan.

JIAT yang ada di kabupaten Timor Tengah Utara ini berjumlah 56 (lima puluh enam) titik dan keseluruhan lokasi belum pernah dilakukan survei-identifikasi tahun sebelumnya. Untuk kecamatan Insana Utara terdapat 5 sumur bor yang pemanfaatannya untuk jaringan irigasi air tanah (JIAT) yaitu : (1) Sumur Bor POI - 90 di desa Oesoko, debit 
sumur diperkiraan $9.52 \mathrm{l} / \mathrm{dt}$ dengan kedalaman $60 \mathrm{~m}$, areal sawah $9.52 \mathrm{Ha}$, selain untuk JIAT juga digunakan kebutuhan air baku. (2) Sumur Bor POI-91 di desa Oesoko, debit sumur diperkiraan $10 \mathrm{l} / \mathrm{dt}$, areal sawah $10 \mathrm{Ha}$, pemanfaatan untuk JIAT, (3) Sumur Bor POI 92 di desa Oelpuah, debit sumur diperkiraan 10 l/dt dengan kedalaman $70 \mathrm{~m}$, areal sawah 10 Ha, pemanfaatan untuk JIAT (4) Sumur Bor POI - 93 di desa Kaubele 1, debit sumur diperkiraan $10 \mathrm{l} / \mathrm{dt}$ dengan kedalaman $65 \mathrm{~m}$, areal sawah $10 \mathrm{Ha}$, pemanfaatan untuk JIAT, (5) Sumur Bor POI - 95 di desa Kaubele 2 , debit sumur diperkiraan $9.5 \mathrm{l} / \mathrm{dt}$ dengan kedalaman $70 \mathrm{~m}$, areal sawah $9.5 \mathrm{Ha}$, pemanfaatan untuk JIAT.

\section{Survey dan Identifikasi}

kegiatan survey dan identifikasi dilaksanakan mengetahui berbagai masalah atau kebutuhan program yang diinginkan. Untuk mengetahui berbagai sumber yang dapat dimanfaatkan untuk pendukung pelaksanaan program dan mempermudah dalam menyusun rencana program yang akan dilaksanakan. Pada tahapan ini dilakukan inventarisas dan identifikasi terhadap lokasi - lokasi sumur bor dan JIAT yang ada di bagi dalam 4 tahap pekerjaan yakni :

Adapun komponen yang diinventarisasi adalah sebagai berikut :

1. Prasarana Fisik meliputi : a. Cek kinerja mesin penggerak, b. Cek kinerja pompa, c.Cek, kinerja rumah pompa, d. Cek kinerja sumur bor, e. Cek kinerja bangunan outlet, f. Cek kinerja saluran pembawa
2. Produktivitas Tanam meliputi : a. Cek tingkat pemenuhan kebutuhan air, b.Cek realisasi luas tanam, c. Cek tingkat produktivitas padi, d. Cek tingkat produktivitas palawija, e. Cek nilai panen dibanding biaya yang dikeluarkan petani.

3. Sarana Penunjang meliputi : a. Cek kinerja riser pipe/air valve, b. Cek kinerja jalan inspeksi, c. Cek kinerja pagar pengaman, d. Cek kinerja kantor OP, e. Cek kinerja rumah operator, f. Cek kinerja alat transportasi, g. Cek kinerja alat komunikasi, h.Cek kinerja alat OP

4. Organisasi Personalia meliputi : a. Cek keberadaan organisasi. b.Cek kelengkapan organisasi, c. Cek kejelasan tugas dan wewenang personil, d. Cek kualifikasi dan kompetensi personil.

5. Dokumentasi meliputi : a. Cek dokumen perencanaan, b. Cek dokumen pembangunan, c. Cek dokumen hokum, d. P3AT, e. Cek kelembagaan P3AT, f. Cek peran aktif P3AT dalam OP, g. Cek partisipasi P3AT dalam penanganan kerusakan, h. Cek kesediaan P3AT dalam pembiayaan OP, i. Cek pertemuan rutin P3AT, j. Cek kelengkapan struktur organisasi, k. Cek kejelasan tugas dan wewenang, I. Cek peran aktif P3AT dalam pengembangan SDM

Tabel 2 dibawah ini memperlihatkan hasil identifikasi dan permasalahan JIAT di Kecamatan Insana Utara Kabupaten Timor Tengah Utara.

Tabel 2 Hasil Survey dan Indentifikasi Sumur JIAT

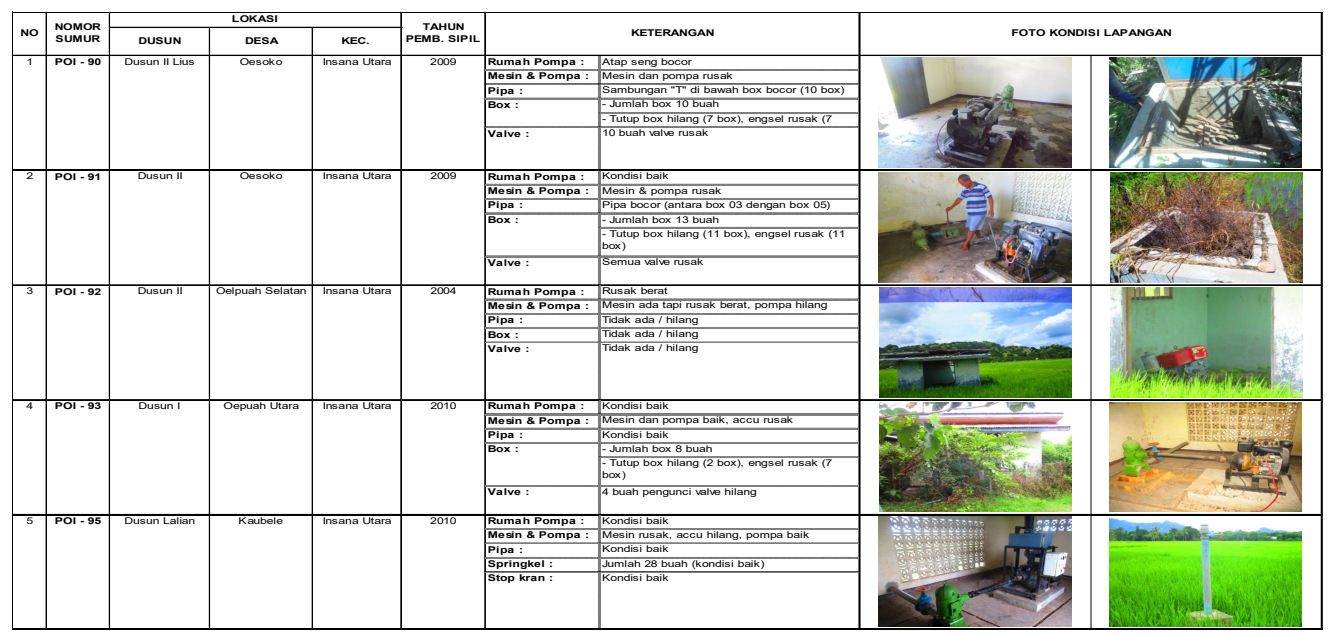


Tabel 3 Penilaian Kinerja jaringan irigasi air tanah (JIAT) Sumur POI-90

Blangko Penilaian Kinerja JIAT

Nomor Sumur POI - 90 Desa Oesoko (Dusun 02 Lius) Kecamatan Insana Utara Kabupaten Timur Tengah Utara

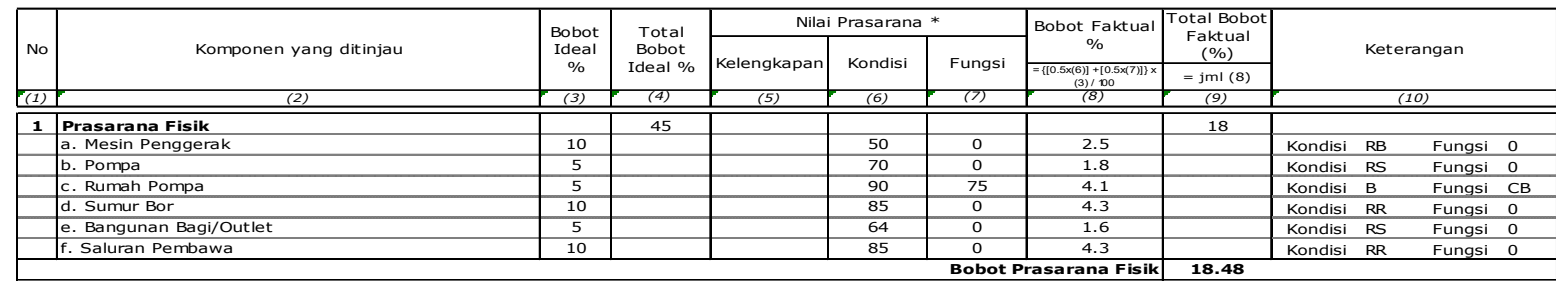

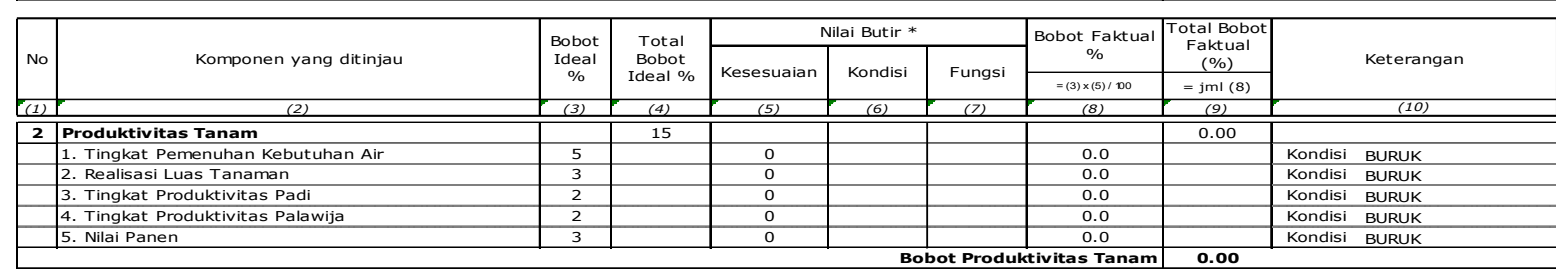

\begin{tabular}{|c|c|c|c|c|c|c|c|c|c|c|c|c|}
\hline \multirow{3}{*}{ No } & \multirow{3}{*}{ Komponen yang ditinjau } & \multirow{3}{*}{$\begin{array}{c}\text { Bobot } \\
\text { Ideal } \\
\%\end{array}$} & \multirow{3}{*}{$\begin{array}{c}\text { Total } \\
\text { Bobot } \\
\text { Ideal \% }\end{array}$} & \multicolumn{3}{|c|}{ Nilai Prasarana * } & \multirow{3}{*}{\begin{tabular}{|c} 
Bobot Faktual \\
$\%$
\end{tabular}} & \multirow{2}{*}{\begin{tabular}{|c|}
$\begin{array}{c}\text { Total Bobot } \\
\text { Faktual } \\
(\%)\end{array}$ \\
\end{tabular}} & \multirow{2}{*}{\multicolumn{4}{|c|}{ Keterangan }} \\
\hline & & & & \multirow{2}{*}{ Kelengkapan } & \multirow{2}{*}{ Kondisi } & \multirow{2}{*}{ Fungsi } & & & & & & \\
\hline & & & & & & & & $=\mathrm{jml}(8)$ & & & & \\
\hline$(1)$ & (2) & (3) & (4) & (5) & (6) & (7) & (8) & (9) & \multicolumn{4}{|c|}{ (10) } \\
\hline \multirow[t]{10}{*}{3} & Sarana Penunjang & & 10 & & & & & 2.9 & & & & \\
\hline & 1. Riser Pipe/Air Valve & 1.0 & & & 90 & 0 & 0.5 & & Kondisi & B & Fungsi & 0 \\
\hline & 2. Jalan Inspeksi & 2.0 & & & 60 & 60 & 1.2 & & Kondisi & 0 & Fungsi & BRK \\
\hline & 3. Pagar Pengaman & 2.0 & & & 60 & 60 & 1.2 & & Kondisi & 0 & Fungsi & BRK \\
\hline & 4. Kantor OP & 1.0 & & & 0 & 0 & 0.0 & & Kondisi & - & Fungsi & - \\
\hline & 5. Rumah Operator & 1.0 & & & 0 & 0 & 0.0 & & Kondisi & - & Fungsi & - \\
\hline & 6. Alat Transportasi & 1.0 & & & 0 & 0 & 0.0 & & Kondisi & - & Fungsi & - \\
\hline & 7. Alat Komunikasi & 1.0 & & & 0 & 0 & 0.0 & & Kondisi & - & Fungsi & - \\
\hline & 8. Alat OP & 1.0 & & & 0 & 0 & 0.0 & & Kondisi & - & Fungsi & - \\
\hline & \multicolumn{7}{|c|}{ Bobot Sarana Penunjang } & 2.85 & & & & \\
\hline
\end{tabular}

\begin{tabular}{|c|c|c|c|c|c|c|c|c|c|}
\hline \multirow{3}{*}{ No } & \multirow{3}{*}{ Komponen yang ditinjau } & \multirow{3}{*}{$\begin{array}{c}\text { Bobot } \\
\text { Ideal } \\
\%\end{array}$} & \multirow{3}{*}{$\begin{array}{c}\text { Total } \\
\text { Bobot } \\
\text { Ideal \% }\end{array}$} & \multicolumn{3}{|c|}{ Nilai Butir* } & \multirow{2}{*}{$\begin{array}{c}\text { Bobot Faktual } \\
\% \\
\end{array}$} & \multirow{2}{*}{\begin{tabular}{|c|}
$\begin{array}{c}\text { Total Bobot } \\
\text { Faktual } \\
(\%)\end{array}$ \\
\end{tabular}} & \multirow{3}{*}{ Keterangan } \\
\hline & & & & \multirow{2}{*}{ Kelengkapan } & \multirow{2}{*}{ Kondisi } & \multirow{2}{*}{ Fungsi } & & & \\
\hline & & & & & & & $=(3) \times(5) / 100$ & $=\mathrm{jml}(8)$ & \\
\hline (1) & (2) & (3) & (4) & (5) & (6) & (7) & $(8)$ & (9) & (10) \\
\hline \multirow[t]{6}{*}{4} & Organisasi Personalia & & 10 & & & & & 0 & \\
\hline & 1. Keberadaaan Organisasi & 2.0 & & 0 & & & 0.0 & & Kondisi KURANG \\
\hline & 2. Kelengkapan Organisasi & 2.0 & & 0 & & & 0.0 & & Kondisi KURANG \\
\hline & 3. Kejelasan Tugas dan Wewenang & 3.0 & & 0 & & & 0.0 & & Kondisi KURANG \\
\hline & 4. Kualifikasi dan Kompetensi Personil & 3.0 & & 0 & & & 0.0 & & Kondisi KURANG \\
\hline & \multicolumn{7}{|c|}{ Bobot Organisasi Personalia } & \multicolumn{2}{|l|}{0.00} \\
\hline
\end{tabular}




\begin{tabular}{|c|c|c|c|c|c|c|c|c|c|}
\hline \multirow{3}{*}{ No } & \multirow{3}{*}{ Komponen yang ditinjau } & \multirow{3}{*}{$\begin{array}{c}\text { Bobot } \\
\text { Ideal } \\
\%\end{array}$} & \multirow{3}{*}{$\begin{array}{c}\text { Total } \\
\text { Bobot } \\
\text { Ideal \% }\end{array}$} & \multicolumn{3}{|c|}{ Nilai Butir * \% } & \multirow{2}{*}{\begin{tabular}{|c} 
Bobot Faktual \\
$\%$
\end{tabular}} & \multirow{2}{*}{\begin{tabular}{|c|}
$\begin{array}{c}\text { Total Bobot } \\
\text { Faktual } \\
(\%)\end{array}$ \\
\end{tabular}} & \multirow{3}{*}{ Keterangan } \\
\hline & & & & \multirow{2}{*}{ Kelengkapan } & \multirow{2}{*}{ Kondisi } & \multirow{2}{*}{ Fungsi } & & & \\
\hline & & & & & & & $=(3) \times(5) / 100$ & $=\mathrm{jmI}(8)$ & \\
\hline$(1)$ & (2) & (3) & (4) & $(5)$ & (6) & $(7)$ & $(8)$ & (9) & $(10)$ \\
\hline \multirow{2}{*}{\begin{tabular}{l|l}
5 & D \\
& 1
\end{tabular}} & \multicolumn{9}{|l|}{ Dokumentasi JIAT } \\
\hline & 1. Dokumen Perencanaan & & 2 & & & & & 2.0 & \\
\hline & a. Gambar Teknik & 0.40 & & 100 & & & 0.4 & & Kondisi BAIK \\
\hline & b. Spesifikasi & 0.30 & & 100 & & & 0.3 & & Kondisi BAIK \\
\hline & c. Nota Desain & 0.30 & & 100 & & & 0.3 & & Kondisi BAIK \\
\hline & d. Manual OP & 0.50 & & 100 & & & 0.5 & & Kondisi BAIK \\
\hline & e. Peta Daerah Irigasi & 0.10 & & 100 & & & 0.1 & & Kondisi BAIK \\
\hline & f. Skema Rencana Pembagian dan Pemberian Air & 0.20 & & 100 & & & 0.2 & & Kondisi BAIK \\
\hline & g. Skema Jaringan Irigasi & 0.20 & & 100 & & & 0.2 & & Kondisi BAIK \\
\hline & 2. Dokumen Pembangunan & & 2 & & & & & 1.6 & \\
\hline & a. Kontrak Pembangunan & 0.50 & & 100 & & & 0.5 & & Kondisi BAIK \\
\hline & b. As Built Drawing & 0.30 & & 100 & & & 0.3 & & Kondisi BAIK \\
\hline & c. Dokumen Uji Pengaliran & 0.50 & & 100 & & & 0.5 & & Kondisi BAIK \\
\hline & d. Dokumen Final Hand Over (FHO) & 0.30 & & 100 & & & 0.3 & & Kondisi BAIK \\
\hline & 3. Dokumen Hukum & & 1 & & & & & 1.0 & \\
\hline & a. Surat Tanah & 0.25 & & 100 & & & 0.3 & & Kondisi BAIK \\
\hline & b. Izin Mendirikan Bangunan (IMB) & 0.25 & & 100 & & & 0.3 & & Kondisi BAIK \\
\hline & c. Izin Lingkungan & 0.25 & & 100 & & & 0.3 & & Kondisi BAIK \\
\hline & d. Surat Kesepakatan Pembagian Tugas & 0.25 & & 100 & & & 0.3 & & Kondisi BAIK \\
\hline & & & & & & Bobc & Dokumentasi & 4.60 & \\
\hline \multirow{3}{*}{ No } & \multirow{3}{*}{ Komponen yang ditinjau } & \multirow{3}{*}{$\begin{array}{c}\text { Bobot } \\
\text { Ideal } \\
\%\end{array}$} & \multirow{3}{*}{$\begin{array}{c}\text { Total } \\
\text { Bobot } \\
\text { Ideal \% }\end{array}$} & \multicolumn{3}{|c|}{ Nilai Butir* } & Bobot Faktual & Total Bobot & \multirow{3}{*}{ Keterangan } \\
\hline & & & & Kolonganol & Kondici & Eungai & $\%$ & $\begin{array}{c}\text { Faktual } \\
(\%)\end{array}$ & \\
\hline & & & & Kelengkapan & Konalsi & rungsi & $=(3) \times(5) / 100$ & $=j \mathrm{ml}(8)$ & \\
\hline (1) & (2) & (3) & (4) & (5) & (6) & (7) & $(8)$ & (9) & (10) \\
\hline \multirow[t]{9}{*}{6} & Petani Pemakai Air Tanah (P3AT) & & 15 & & & & & 9 & \\
\hline & 1. Kelembagaan P3AT sudah berbadan Hukum & 3.0 & & 90 & & & 2.7 & & Kondisi BAIK \\
\hline & 2. Peran Aktif P3AT dalam pelaksanaan operasi JIAT & 2.0 & & 50 & & & 1.0 & & Kondisi KURANG \\
\hline & 3. Partisipasi P3AT dalam penanganan kerusakan JIAT & 2.0 & & 50 & & & 1.0 & & Kondisi KURANG \\
\hline & 4. Kesediaan P3AT untuk pembiayaan kegiatan OP & 1.0 & & 50 & & & 0.5 & & Kondisi KURANG \\
\hline & 5. Pelaksanaan Pertemuan Rutin & 1.0 & & 40 & & & 0.4 & & Kondisi KURANG \\
\hline & 6. Kelengkapan struktur organisasi & 1.0 & & 80 & & & 0.8 & & Kondisi BAIK \\
\hline & 7. Kejelasan tugas dan wewenang & 3.0 & & 60 & & & 1.8 & & Kondisi KURANG \\
\hline & 8. Peran aktif P3AT dalam pengembangan SDM & 2.0 & & 30 & & & 0.6 & & Kondisi KURANG \\
\hline \multicolumn{8}{|r|}{ Bobot P3AT } & 8.80 & \\
\hline & & & & & & & Total Bobot & 34.73 & $\begin{array}{c}\text { Kinerja jelek dan perlu } \\
\text { perhatian }\end{array}$ \\
\hline
\end{tabular}

Hasil Akhir Penilaian Kinerja JIAT

Nomor Sumur POI - 90 Desa Oesoko (Dusun 02 Lius) Kecamatan Insana Utara Kabupaten Timur Tengah Utara

\begin{tabular}{|c|c|c|c|c|c|}
\hline No & Komponen yang ditinjau & $\begin{array}{c}\text { Bobot Hasil } \\
\text { Kinerja } \\
\%\end{array}$ & $\begin{array}{l}\text { Nilai } \\
\%\end{array}$ & Kategori & Rencana Tindak Lanjut \\
\hline 1 & 2 & 3 & 4 & 5 & 6 \\
\hline 1 & Prasarana Fisik & 41.06 & $\begin{array}{l}>75 \% \\
51-75 \% \\
\mathbf{2 6 - 5 0 \%} \\
<20 \%\end{array}$ & $\begin{array}{l}\text { Baik } \\
\text { Rusak Ringan } \\
\text { Rusak Sedang } \\
\text { Rusak Berat }\end{array}$ & $\begin{array}{l}\text { Pemeliharaan Rutin } \\
\text { Pemeliharaan Berkala } \\
\text { Pemeliharaan Berkala } \\
\text { Perbaikan Berat/ Penggantian/ Perbaikan } \\
\text { Darurat / Rehabilitasi }\end{array}$ \\
\hline 2 & Produktivitas Tanam & 0.00 & $\begin{array}{l}>70 \% \\
50-70 \% \\
<50 \%\end{array}$ & $\begin{array}{l}\text { Baik } \\
\text { Cukup } \\
\text { Buruk }\end{array}$ & $\begin{array}{l}\text { Upaya Peningkatan } \\
\text { Upaya Peningkatan } \\
\text { Kaji Ulang }\end{array}$ \\
\hline 3 & Sarana Penunjang & 28.50 & $\begin{array}{l}>75 \% \\
51-75 \% \\
\mathbf{2 6 - 5 0 \%} \\
<20 \%\end{array}$ & $\begin{array}{l}\text { Baik } \\
\text { Rusak Ringan } \\
\text { Rusak Sedang } \\
\text { Rusak Berat }\end{array}$ & $\begin{array}{l}\text { Pemeliharaan Rutin } \\
\text { Pemeliharaan Berkala } \\
\text { Pemeliharaan Berkala } \\
\text { Perbaikan Berat/ Penggantian/ Perbaikan } \\
\text { Darurat / Rehabilitasi }\end{array}$ \\
\hline 4 & Organisasi Personalia & 0.00 & $\begin{array}{l}>70 \% \\
50-70 \% \\
\leq \mathbf{5 0} \%\end{array}$ & $\begin{array}{l}\text { Baik } \\
\text { Cukup } \\
\text { Buruk }\end{array}$ & $\begin{array}{l}\text { Upaya Peningkatan } \\
\text { Upaya Peningkatan } \\
\text { Kaji Ulang }\end{array}$ \\
\hline 5 & Dokumentasi JIAT & 92.00 & $\begin{array}{l}>70 \% \\
50-70 \% \\
<50 \%\end{array}$ & $\begin{array}{l}\text { Baik } \\
\text { Cukup } \\
\text { Buruk }\end{array}$ & $\begin{array}{l}\text { Upaya Peningkatan } \\
\text { Upaya Peningkatan } \\
\text { Kaji Ulang }\end{array}$ \\
\hline 6 & Petani Pemakai Air Tanah (P3AT) & 58.67 & $\begin{array}{c}>70 \% \\
50-70 \% \\
<50 \%\end{array}$ & $\begin{array}{l}\text { Baik } \\
\text { Cukup } \\
\text { Buruk }\end{array}$ & $\begin{array}{l}\text { Upaya Peningkatan } \\
\text { Upaya Peningkatan } \\
\text { Kaji Ulang }\end{array}$ \\
\hline
\end{tabular}


Tabel 4. Rangking hasil penilaian kinerja jaringan irigasi air tanah (JIAT) di Kecamatan Insana Utara kabupaten Timor Tengah Utara.

\begin{tabular}{|c|c|c|c|c|c|c|c|c|}
\hline \multirow{2}{*}{ No } & \multirow{2}{*}{$\begin{array}{c}\text { Nama } \\
\text { Sumur }\end{array}$} & \multicolumn{3}{|c|}{ Letak / Lokasi } & \multirow{2}{*}{ Kinerja } & \multicolumn{3}{|c|}{ Keterangan } \\
& Dusun & Desa & Kecamatan & JIAT (\%) & Kinerja JIAT & Peruntukan & Jumlah \\
\hline 2 & POI 92 & Dusun 2 & Oelpuah Selatar & Insana Utara & 10 & $\begin{array}{c}\text { Kinerja jelek dan perlu } \\
\text { perhatian }\end{array}$ & JIAT \\
\hline 3 & POI 93 & Dusun 1 & Oelpuah Utara & Biboki Utara & 31 & $\begin{array}{c}\text { Kinerja jelek dan perlu } \\
\text { perhatian }\end{array}$ & JIAT \\
\hline 4 & POI 95 & $\begin{array}{c}\text { Dusun IV, } \\
\text { Lalian }\end{array}$ & Kaubele & Insana Utara & 32 & $\begin{array}{c}\text { Kinerja jelek dan perlu } \\
\text { perhatian }\end{array}$ & JIAT \\
\hline 5 & POI 90 & Dusun 02, Lius & Oesoko & Insana Utara & 35 & $\begin{array}{c}\text { Kinerja jelek dan perlu } \\
\text { perhatian }\end{array}$ & JIAT \\
\hline
\end{tabular}

\section{PenilaianKinerja JIAT}

Pekerjaan analisa data diawali dengan proses penilaian kinerja asset JIAT untuk menilai berapa besar tingkat layanan asset tersebut pada kondisi saat ini. Kegiatan ini berpedoman kepada PERMEN PUPR NO. 23 Tahun 2015 tentang "Teknis Perencanaan Pengelolaan Aset Irigasi".

Tahapan yang dilakukan dalam kegiatan analisa data diurutkan sebagai berikut:

1. Pengelompokkan data hasil survei berdasarkan lokasi JIAT.

2. Penilaian kinerja JIAT dengan pedoman PERMEN PUPR NO. 23 Tahun 2015

Tabel 3 memperlihatkan Penilaian Kinerja jaringan irigasi air tanah (JIAT) Sumur No POI-90.

\section{PENUTUP}

\section{Kesimpulan}

1. Secara umum pemanfaatan JIAT yang ada termasuk yang saat ini masih dalam kondisi baik, tidak optimal, tidak digunakan untuk musim tanam kedua, atau kalaupun digunakan hanya untuk area yang sangat minim.

2. Melihat kondisi terkini dari infrastruktur JIAT yang ada maka sesungguhnya JIAT yang ada tidak menjamin kepastian panen walaupun hanya untuk sekali tanam.

3. Menyimak resume hasil analisis kondisi kinerja JIAT DI Kecamatan Insana Utara Kabupaten Timor Tengah Utara maka ada 1 (tiga) lokasi dengan kinerja 10 (sepuluh persen) dan 4 lokasi lainnya dengan kinerja dibawah 50\% ( Kinerja jelek dan perlu perhatian).
4. Permasalahan yang terjadi di Kab. TTU banyak boks yang tidak berfungsi dan sulit diketahui dengan pasti kondisinya karena kerusakan pada genset dan pompa.

5. Secara keseluruhan setiap rumah pompa tidak memiliki buku petunjuk operasi dan pemeliharaa, lembar operasional mesin, maupun prosedur pelaporan kerusakan

\section{Saran}

1. Diperlukan sosialisasi pemanfaatan JIAT yang lebih massif di wilayah ini sebelum dilakukan kegiatan pemeliharaan/pergantian, agar dikemudian hari partisipasi petani dalam menggunakan maupun memelihara infrastruktur terbangun menjadi lebih baik.

2. Perlu dilakukan tindakan pemeliharaan/pergantian dilakukan berdasarkan skala prioritas.

3. Untuk peningkatan produktifitas tanaman pangan (Padi maupun palawija) perlu dilakukan perbaikan komponen system jaringan dengan benar dan pengoperasin dan pemeliharaan yang teratur dan benar..

\section{DAFTAR PUSTAKA}

Soemarto, C.D. (1989). Hidrologi Teknik. Usaha Nasional, Surabaya.

Asdak, C. (2001). Hidrologi dan Pengelolaan Daerah Aliran Sungai. Gadjah Mada University Press, Yogyakarta.

Departemen Pekerjaan Umum, Peraturan Menteri Pekerjaan Umum Nomor 
32/PRT/M/2007 tentang Pedoman Operasi dan Pemeliharaan Jaringan Irigasi, Jakarta.

Departemen Pekerjaan Umum, Peraturan Menteri Pekerjaan Umum dan Perumahan Rakyat Nomor 12/PRT/M/2015 tentang Eksploitasi dan Pemeliharaan Jaringan Irigasi, Jakarta.

Departemen Pekerjaan Umum, Peraturan Menteri Pekerjaan Umum dan Perumahan Rakyat Nomor 23/PRT/M/2015 tentang Pengelolaan Aset Irigasi, Jakarta

Joesron Loebis.(1992). Bangunan Air.Yayasan Badan Penerbit Pekerjaan Umum Jakarta.

Soewarno. (1995). Hidrologi. Nova, Bandung.

Sobriyah. (2005), Sistem Pendukung Keputusan Pada Penentuan Prioritas Rehabilitasi Jaringan Irigasi di DIY. Gema Teknik Fakultas Teknik Universitas Sebelas Maret

Supriharyono. (2002), Intisari Materi Kuliah Metodologi Penelitian, Program Pasca Sarjana Universitas Diponegoro Magister Teknik Sipil. 